\title{
New Integrated Networks for Monitoring Seismic and Tsunami Activity in Morocco
}

\author{
Abdelouahad Birouk ${ }^{1}$, Aomar Ibenbrahim*,1, Azelarab El Mouraouah ${ }^{1}$ and \\ Mohamed Kasmi ${ }^{2}$ \\ (1) Geophysics \& Natural Risks Laboratory, Scientific Institute, GEOPAC research Center, Mohammed V University, \\ Rabat, Morocco \\ (2) National Institute of Geophysics, National Center for Scientific and Technical Research (CNRST), Rabat, Morocco
}

Article history: received October 2, 2018; accepted October 24, 2019

\begin{abstract}
A number of networks are currently being deployed for the real-time seismic and sea-level monitoring within Morocco, which has historically known several destructive earthquakes. In particular, a new seismic network that relies on satellite transmission for real-time data acquisition is being deployed in the country and consists of a hub for the management of VSAT and 48 seismic stations, all connected to a Central acquisition, processing and data storage Unit in Rabat. In addition, a seismic array consisting of 10 high-detection seismic stations is also connected by VSAT to the Rabat central recording site.

A strong-motion network consisting of 70 instruments is installed for the seismic monitoring of large infrastructures. These instruments have allowed the recording, so far, of more than 40 accelerograms. A second set of 50 digital accelerographs is currently being deployed in urban centers in order to rapidly provide maps of estimated damage distribution following a significant earthquake. Moreover, a new network of seven tide-gauges for sea level monitoring is being installed along Moroccan coasts. Combined with the above-mentioned seismic network and an installed tsunami analysis system, this tide-gauges network aims at setting up in the near future, a center for early warning against tsunamis.

Compared to the previous network, the new network has allowed the recording of five times more events per year and helped lower the threshold of detected magnitudes. A 24/7 surveillance has been set up for this monitoring and for providing rapid seismic warning to national authorities in charge of seismic risk management.
\end{abstract}

Keywords: Seismic monitoring; Seismic warning; Morocco seismic network; Tsunami; Accelerographs, Tide-gauges.

\section{Introduction}

The National Institute of Geophysics of Morocco (INGM) is currently deploying new networks instrumentation for real-time monitoring of the seismic activity in Morocco and its neighboring regions. This instrumentation constitutes an important enhancement of the seismic information system in the country.

Morocco is located at the extreme Northwest of Africa and has known during its history some violent and 


\section{Abdelouahad Birouk et al.}

destructive earthquakes such as the Agadir M6.0 earthquake of February 29, 1960 (Figure 1) that caused more than 12,000 deaths and an extensive destruction of the city (El Mrabet 2005). In October 1992, two M=5.2 earthquakes occurred near the cities of Rissani and Erfoud in the south-east of Morocco [Bensaid et al., 2012]. More recently, the $\mathrm{Al}$ Hoceima region (north of Morocco) underwent three important earthquakes; an M=5.8 in 1994 (Ibenbrahim et al., 1994), a M=6.3 event in 2004 [El Mouraouah et al., 2004] and another $M=6.3$ earthquake offshore Al Hoceima in 2016 [Kariche et al., 2018]. All these destructive Al Hoceima events were followed by seismic sequences that lasted nearly a year, and led a large population to migrate and leave the town.



Figure 1. Seismicity map of northern Morocco and its neighboring regions showing earthquakes with magnitudes higher than or equal to M5.0 for the period 1900 to February 2017. Yellow circles are events with $5.0 \leq \mathrm{M} \leq 5.9$, green circles are events with $6.0 \leq \mathrm{M} \leq 6.9$ and red circles are events with magnitudes higher than M7.0. The red star is the November 1, 1755 Lisbon earthquake. Seismic data are compiled from the INGM catalogue (1989-2016), from Pelaez et al. (2007) and the ISC-GEM Global Instrumental Earthquake Catalogue version 5.1.

Seismic networks are crucial to observe and monitor earthquake activity. Following the 1960 Agadir earthquake, the Moroccan Government had decided to deploy the first seismic network in the country. This analog network consisted of 15 short period stand-alone stations that ran in the period of 1964 till the end of the eighties.

In 1982, the Counsel of the Arab Ministers of the Habitat adopted a Programme for the Assessment and Mitigation of Earthquake Risk in the Arab region (PAMERAR) which was implemented by the UNESCO. Morocco was one of the countries that benefited most from this program. Thus, since 1986, a second seismic network was deployed in the country. This analog network consisted of over 30 seismic stations, most of which used radio and phone telemetry and allowed to follow the seismic activity in Morocco in real-time. This network was installed and further run by the INGM until 2012.

By the year 2009, this telemetered network became obsolete and the INGM decided to install new instrumentation networks based on new technology. The new third generation seismic network is currently composed of a larger number of seismic stations that will cover the whole territory of Morocco, from the city of 
Tangier in the extreme north to the Mauritania border in the south. This network is further augmented by a strongmotion network deployed for monitoring the large infrastructures of the country and for producing shakemaps in quasi real-time, as well as by a tide-gauges network to eventually set up a tsunami warning system.

In this paper, we present an overview of the design and implementation of this new instrumentation deployed in the Moroccan territory for the seismic and tsunami monitoring.

\section{National seismic and tide-gauges networks}

\subsection{Mission}

A seismic observing and warning system should enable to monitor the seismic activity in real time in order to inform the population and especially the intervention teams involved in a seismic crisis management. The communicated seismic messages provide fast and accurate information on the location and magnitude of an eventual earthquake as soon as it occurs. This basic information is very important since it already gives an idea on potential damages induced by the shaking. Moreover, shakemaps provide a more detailed estimate of the intensity distribution of the shaking in the region which can be used to assess the possible distribution of damages. Thanks to this information, onsite interventions after the occurrence of a destructive event are focused on the disaster area with appropriate means, thereby helping to save human lives. Moreover, in case of a major marine earthquake, the tidal gauges should also provide timely confirmation of a potential alert issued with regards to incoming tsunami.

The main objectives of this new network in Morocco is to ensure a fairly dense distribution of seismic stations in order to record all seismic activity potentially felt by the population $(M \geq 2.5)$ within all the national territory, as well as to be able to provide critical users with timely warning messages for any earthquake with a magnitude $\geq 3.5$. The datasets produced by such networks are very valuable for scientists who extract important seismological information through scientific research.

This seismic network is designed to perform as most of the modern state-of-the-art surveillance and monitoring earthquake networks [e.g. the Italian network as described by Michelini et al., 2016, also the USA-ANSS network]. Thus, this network is considered as the backbone of the national seismic surveillance and warning system, it is composed in this first phase of about fifty real-time telemetered seismic stations deployed throughout the national territory. It will be used to monitor both continental and offshore seismic activity that affects Morocco. In a second phase, this network will be extended to at least 80 stations. This would help increase density of stations in specific high-risk areas or cover gaps not yet covered by the present network. The seismographic-network is supplemented by a strong motion network for the recording of strong events. Accelerometers are installed either in the urban areas for the needs of monitoring and warning, or for the study of seismic response of large infrastructures (dams, power stations ...). A network of tide gauges is being developed for sea level monitoring, which combined with the real-time seismic network and an already installed tsunami analysis system, will be the base to provide early warning against tsunamis.

Furthermore, new databases on the seismic activity recorded by this network have been set up. These databases include catalogs, bulletins and recorded waveforms and will allow, among other things, through the various studies, the recognition and characterization of the seismic source zones, a better knowledge of the seismotectonics of the region, the assessment of seismic hazard and possibly allow studies of vulnerability and seismic risk and tsunami. Thanks to the use of modern technologies, the instrumentation being installed constitutes the nucleus of an early warning system.

\subsection{The Seismic Network description}

\subsubsection{Seismic stations composition and distribution}

The seismicity recorded by previous networks in the period before 2010 allowed a good knowledge on the distribution of seismic sources in Morocco (Ibenbrahim et al., 2004), which constitutes an important source of information for the configuration, geometry and setting, of the new seismic network. Indeed, the new seismic 


\section{Abdelouahad Birouk et al.}

stations are more numerous and therefore this allows to have a higher density of seismic stations in the Rif region, in the north of the country, which is the most seismically active region in Morocco. The density of seismic stations decreases progressively as one goes south, where there is notably less seismic activity. Thus, in the northern regions of the country, the distribution of sites is designed with approximately a $100 \mathrm{~km}$ average inter-distance between seismic stations. This distance between stations increases in other parts of the country up to $\sim 400 \mathrm{~km}$ in the lessactive southernmost provinces of the national territory.

Installing new stations requires a major effort in terms of sites search, qualification, requests for authorizations, construction of seismic shelters and instruments installation. So far, 30 seismic stations of this network were installed and are functional. The installation of the remaining 18 stations of this phase 1 is already planned throughout the national territory (Figure 2).

The seismological network currently deployed throughout Morocco consists of 30 three-components broadband and short-period seismic stations (Table 1), the Rabat-Mednet VBB (very broadband) observatory (http://mednet.rm.ingv.it/) and the Midelt-СTBTO broadband observatory. In addition, a seismic array consisting of 10 high-detection seismic stations is installed within 2 concentric rings $500 \mathrm{~m}$ and $2 \mathrm{~km}$ in diameter, in the rural community of Zaïda. This network is further complemented by 15 standalone digital seismic stations which can be deployed as temporary stations for aftershock studies in case of a seismic crisis.

The deployment of the new VSAT network represents for the INGM a quantum leap, by replacing and improving the former aging seismic network operated by the INGM between 1988 and 2010. Indeed, the old network was of the first digital type generation consisting in its telemetered part of 30 single-component type short-period stations. The data were then transmitted in an analog form by using UHF radio links and dedicated phone-lines. Digitization and timing were done at the data acquisition, processing and archiving Center in Rabat.

Seismic instrumentation

STS-2, 120 s BB Sensor (Streckeisen)

STS-1, 360 s VBB Sensor (Streckeisen)

Trillium $360 \mathrm{~S}$ (Nanometrics)

Sensors

LE-3Dlite/ 1s (Lennartz electronic $\mathrm{GmbH}$ )

LE-3Dlite/ 5s (Lennartz electronic GmbH)

EpiSensor (Kinemetrics)

\begin{tabular}{ll}
\hline \multirow{2}{*}{ Digitizers } & Q330, 6 channels, 32 Mb,135 dB, 24 bit (Quanterra) \\
& $\begin{array}{l}\text { Q330S, } 3 \text { channels, 32 Mb,Dual USB (2x4Go) 135 dB, 24 bit (Quanterra) } \\
\text { Marslite } 3 \text { channels, 20 bit (Lennartz electronic GmbH) }\end{array}$ \\
\hline Transmission & VSAT (TSAT 3000 receiver at hub \& remote stations), Internet \\
\hline Strong motion Instrumentation & $\begin{array}{l}\text { SSA-1 (Kinemetrics) } \\
\text { Etna (Kinemetrics) } \\
\text { Basalt (Kinemetrics) } \\
\text { GCR16, GSR18 (GeoSIG) }\end{array}$ \\
\hline Sensor & Tide Gauge instrumentation \\
\hline Digitizers & Kalesto radar, OTT RLS radar \\
\hline Transmissions & LoggoSens2, OTT netDL 1000 \\
\hline Antenna & ADSL, GPRS \\
\hline Recorders & GPS instrumentation (not yet deployed) \\
\hline Transmissions & AR10 (Leica Geosystems) \\
\hline
\end{tabular}

Table 1. Characteristics of the new Instrumentation of the Morocco integrated networks. 


\section{Monitoring earthquakes and Tsunami in Morocco}
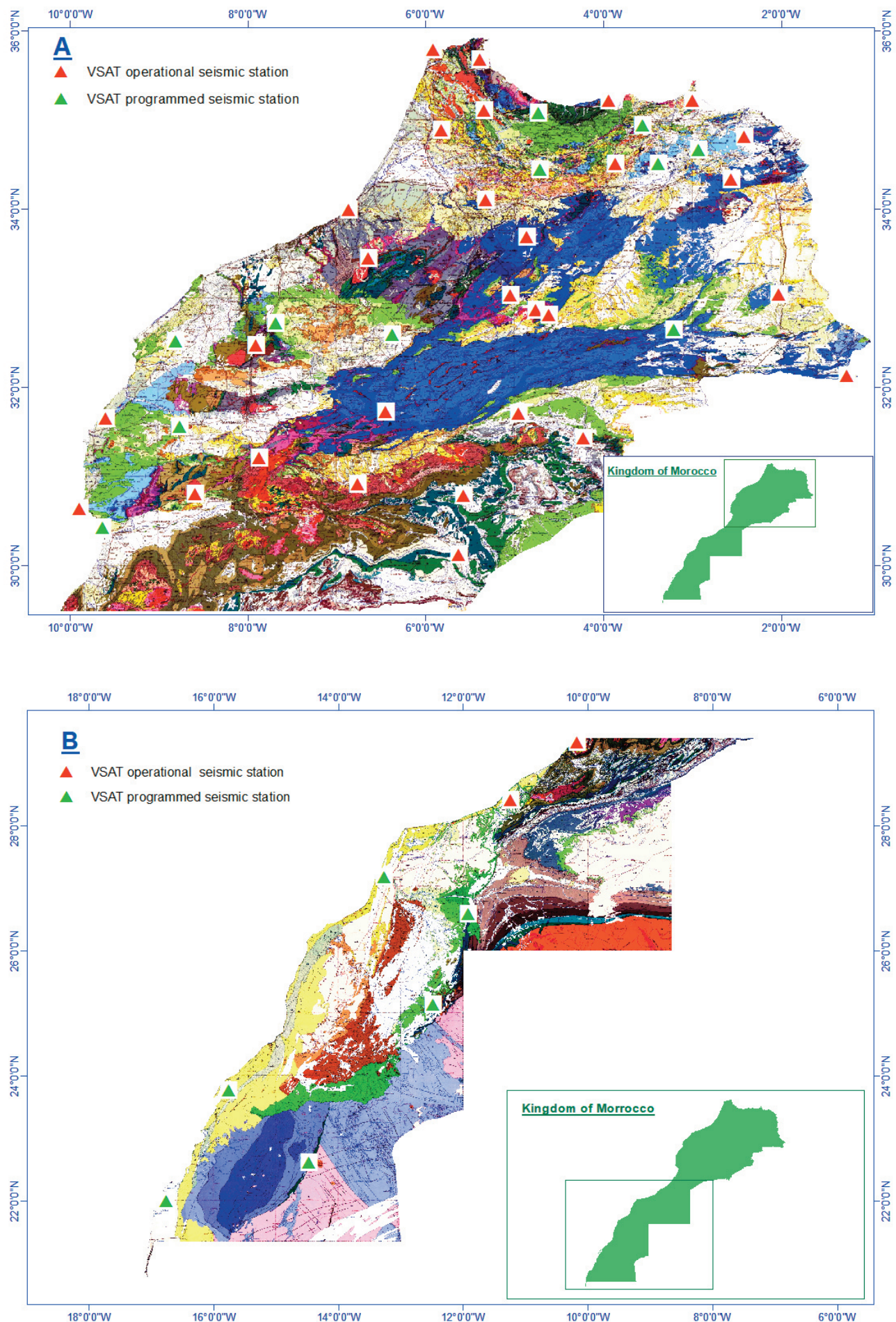

Figure 2. New national seismic network using digital satellite data transmission and acquisition. (A) and (B) maps showing respectively for the northern and southern provinces of Morocco, the seismic stations (red triangles) currently operational and the ones that will soon be installed (green triangles) to attain the installation of the overall expected 48 stations of phase 1.

The significant improvements introduced by the new VSAT seismic network are partly due to a wider coverage of the territory and mostly to the use of a new generation of equipments with higher quality features both at the Rabat acquisition Center and at the seismic stations level. The main improvements concerning the seismic stations can be summarized as follows: 


\section{Abdelouahad Birouk et al.}

Sensitivity, bandwidth and dynamics of seismic sensors: the greater sensitivity of the new network (1500 $\mathrm{V} /(\mathrm{m} / \mathrm{s})$ versus $345 \mathrm{~V} /(\mathrm{m} / \mathrm{s}))$ combined with a high sensitivity of the digitizer which increases the detectability of the system. A bandwidth of 120 secs to $50 \mathrm{~Hz}$ corresponding to a natural frequency of $0.0083 \mathrm{~Hz}$ versus $1 \mathrm{~Hz}$ which makes it possible to cover, in addition to local activity, the regional seismicity as well as other applications such as the dispersion of surface waves, studies of crustal properties etc. The force balance technology of broadband sensors operating near the equilibrium position of masses, allows the detection of strong movements without mechanical clipping contributing to the high dynamic of the system.

Improved digitizing resolution and recorder features: 24 -bit delta-Sigma digitizers versus 16-bit (centralized digitizing at data Rabat Center for the old network), resulting in improved weak signal processing and reduced quantization errors. Also the digitizer presents interesting data acquisition features at the level of gains setting, sampling rate, filtering ....and has broad possibilities for telemetry, sensor control and remote settings.

Transmission quality: VSAT satellite links have unlike the previous analog data transmission system (which used UHF links and dedicated telephone lines), largely improved error detection and correction. The VSAT transmission has also allowed to significantly reduce transmission costs as compared to frequency and telephone line subscription fees and in terms of the needed UHF radio relays costs. This type of transmission, which does not require terrestrial direct visibility as in the case of UHF radio links, nor does-it depend on the GPRS coverage provided by the telecom operator, has also given greater freedom and flexibility in the choice of stations implantation sites.

a)

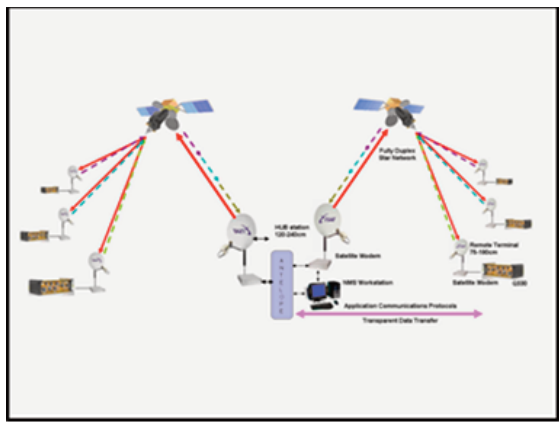

b)
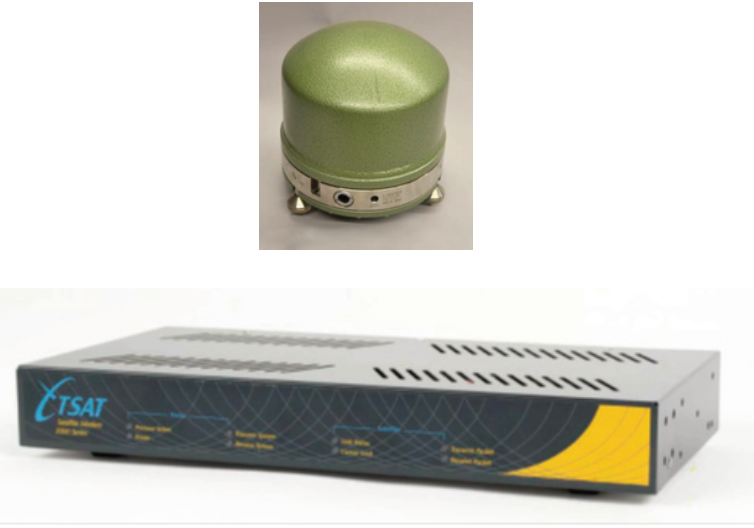

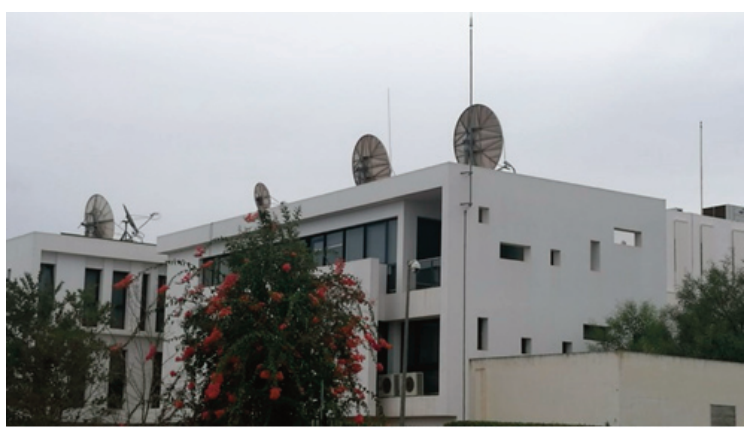

c)
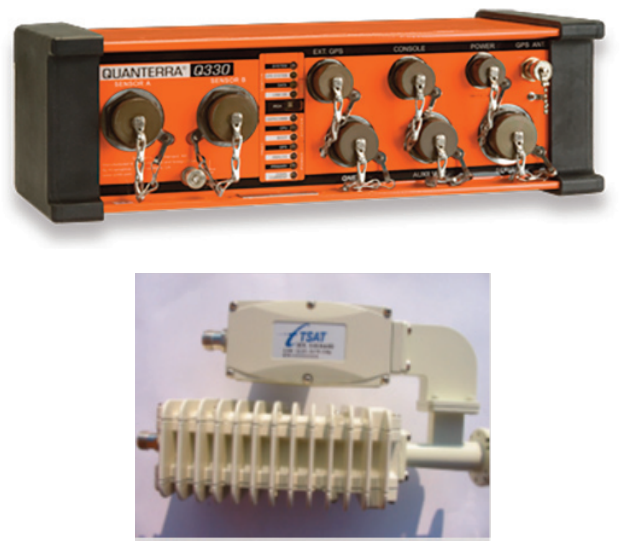

d)

e)

Figure 3. Some illustrations on the Morocco seismic network; (a) A Dual Hub VSAT system at Rabat and the data-reception satellite dishes on the roof of the Rabat INGM building, (b) STS2 Streckeisen 3-Components broad-band seismometer, (c) Q330 Quanterra digitizer, (6 channels, $135 \mathrm{~dB}$ dynamic and 24-bit resolution), (d) VSAT terminal TSAT 3000 (used at remote stations and at the dual hub (master or slave versions)), (e) VSAT BUC (Transmission) and LNB (reception). 
This greater flexibility in the choice of sites makes it possible to deploy stations at good-quality sites where the seismic signal is not contaminated by noise or distorted by local site effects; sites far from sources of both artificial (human activities) and natural (streams, windy sites etc.) noise and more suitable in terms of soil quality (nonfractured hard rock either outcropping at the surface or at shallow depths). Thus, several stations of this network have been installed in granitic soil.

In addition, all stations vaults consist of 2 levels (Figure 4). These vaults have a surface area of about $3 \mathrm{~m}$ by 3 $\mathrm{m}$. The lower level housing the seismometer is at least two meters deep from ground level or more if the hard rock is deeper. In addition, the base supporting the seismic sensor is isolated and mechanically decoupled from the rest of the seismic shelter. The electronic components are installed at the first level, while the data transmission parabola is installed on the roof. All of these factors have resulted in very quiet seismic stations in terms of background noise (Figure 5) with reference to Peterson’s New Low Noise Model (NLNM) [Peterson, 1993].

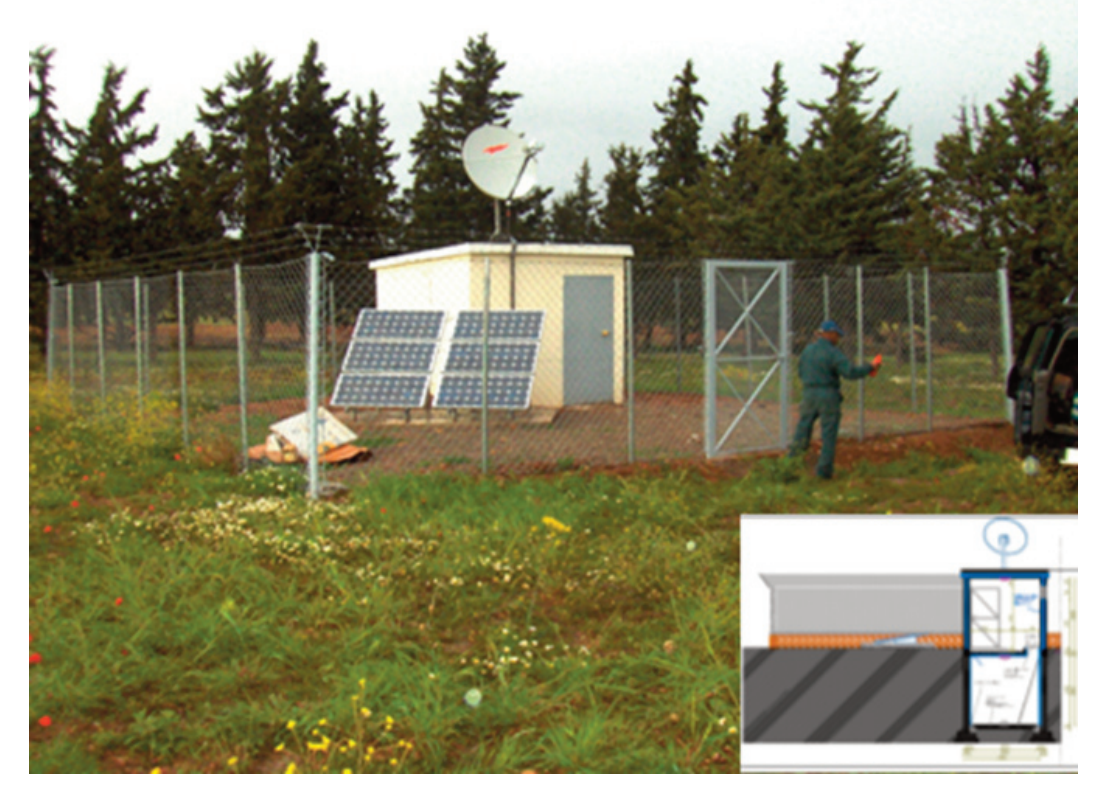

Figure 4. Example of a VSAT two-levels seismic vault, showing the VSAT data-transmission parabola and solar panels. The schematic diagram on the bottom-right shows an overall sketch of a station with the lower level at a depth below surface-level.

The choice of sites with low background noise, the acquisition of high sensitivity seismic sensors, very high resolution digitizers, as well as a suitable distribution and configuration of the stations around the seismogenic zones has resulted in an interesting lowering of the magnitude detectability threshold of the seismic network. As a result, lower magnitude earthquakes are detected and occasionally located with fairly good accuracy in some areas which are well covered by seismic stations, mostly in northern Morocco (negative magnitudes recorded several times in the Al Hoceima region). A number of seismic stations are deployed near the Atlantic and Mediterranean coasts in order to help record events offshore in the Gulf of Cadiz or in the Alboran Sea. Such events can be dangerous for Morocco, both because of their eventual high magnitude and because of tsunamis that they can potentially generate. Thus, combining data from Morocco's broadband seismic network along with real-time data from some Spanish and Portuguese stations allows to better constrain the offshore seismicity.

The quality of equipments of the new seismic network along with the better seismic stations coverage and configuration as well as the real time data sharing have also resulted in a higher number of seismic detected and located events within the national territory and neighboring regions. Thus, this number has increased from an average of 360 events per year (average between 1993 and 2008 for the old network) to more than 2000 locatedevents per year in 2014 for the new network. Also, the broadband technology of the new seismic network has further allowed detecting each year several hundreds of teleseismic events. 


\section{Abdelouahad Birouk et al.}
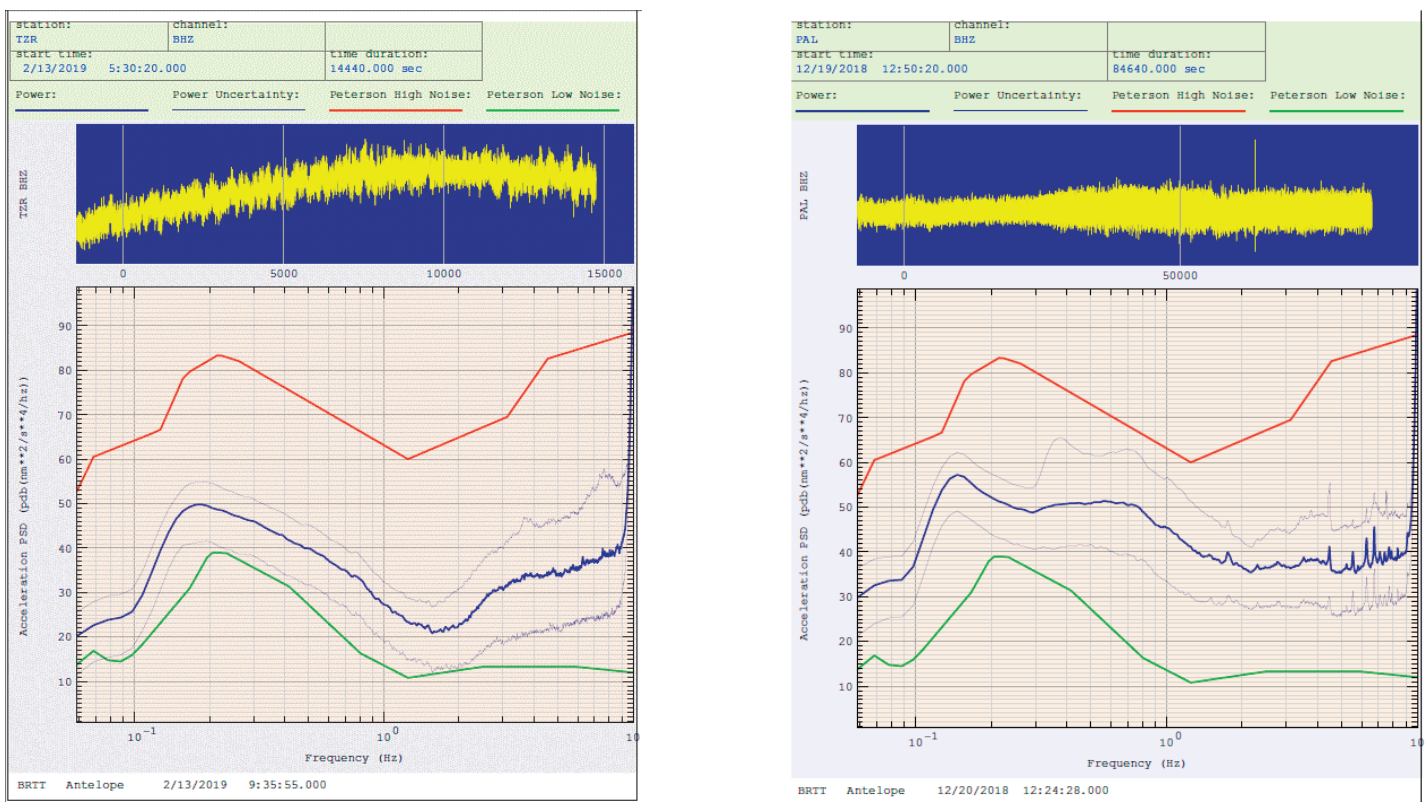

Figure 5. Example of background noise recorded at the TZR Station (Tazarine) (left) and the OUK Station (Oukaïmiden) right, as compared to the Peterson's New Low and High Noise Models (NLNM- green curve, NHNM- red curve).

\subsubsection{The Data Acquisition, Processing, Transmission and Archiving Center}

At the Rabat Operational Center, the Antelope software (e.g., https://kinemetrics.com/wpcontent/uploads/2017/04/datasheet-software-antelope.pdf) is used for the acquisition of real-time seismic data, real-time data processing (detection, location, and magnitude determination, etc.) and data sharing or offline data processing and archiving. Antelope is an open system capable of acquiring seismic or environmental data in packet format from different hardware platforms (dataloggers or data servers) and to a large extent via TCP / IP transmissions over dedicated communications channels (satellite, GPRS ...) or via the Internet.

Real time acquisition: is characterized by a faster automatic location (less than 2 minutes under certain conditions). The system first predetermines the seismic event hypocenter from a grid of points with a spatial resolution, each representing a possible hypocenter, and for which the system has pre-calculated the arrival times for each station of the network and selected the hypocenter that best matches the measured arrival times. In a second step the automatic system uses this location as a starting solution for an iterative calculation minimizing the residues. Another advantage of this new system is that it allows a simultaneous use of several velocity models each corresponding to a geographical area in order to take into account crust variations. Also, this system is characterized by a multiple band triggering detectors (multiple STA, LTA and Filters).

Data Import/export: The possibility of real-time import of data from dataservers such as the Antelope ORB, Comserv, SeedLink, Earthworm etc. ( http://www.brtt.com/docs/dataflow.pdf) makes it possible to considerably extend the local physical seismic network in a virtual extended network. In addition, the functionality of real-time data export to other data servers (Antelope ORB, SeedLink...) makes it compatible for exchanging and sharing data with other seismological centers.

Tele-control: The ability to remotely control in real time a number of parameters (state-of-health information) such as battery charge, GPS status, buffer level, temperature etc. allows on one hand remote diagnostics that can avoid unnecessary trips on site (lower operating cost) and secondly makes it easier to use remote commands such as centering and calibrating sensors, setting up digitizers, satellite transceivers or resetting them etc.

Data storage: is done in a relational database to allow for effective ways to organize and easily access the data. 
VSAT hub: The Rabat Center system is also equipped with a hub for managing satellite links that allows parameterizing transceivers and monitoring the status of data transmission via graphical interfaces (power of the incoming and outgoing signals, incoming and outgoing flows, stops, gaps ...) or by reading log files. Moreover, we have opted to have data transmission go through a dual hub and two satellites, each loading $50 \%$ of the stations of the network, for data transmission, thus, ensuring the reception and connection to at least half of the network stations in case of a break-down of the segments of one of the two satellites.

A multitude of commands for real-time and offline processing counting in hundreds, not to mention scripting languages interfaces and open source extensions made possible by the open architecture of the Antelope system.

At the Rabat Center, the various Antelope features mentioned above (5.3 Release) are supported by three highperformance servers; a server for acquisition and automatic processing, a server for manual processing and for the Shakemap module and the third server for data exchange and the web \& ftp server.

\subsection{The Strong Motion Network}

The strong motion network deployed by the INGM is to meet two objectives. A first set of stations are deployed in sites close to large infrastructures in order to obtain unsaturated recordings in the event of a major earthquake. A second set of accelerometric stations is deployed in larger cities in order to rapidly provide maps of the distribution of peak ground accelerations and/or intensities reflecting an estimate of the damage distribution in urban tissues near the hypocenter of a significant earthquake.

Large infrastrutures Monitoring: The first set of strong motion instruments, which installation began in the 1990s, consists of nearly 70 non-telemetered accelerographs (Figure 6). These equipments have mainly been deployed in large dams for the purpose of their seismic monitoring in the context of an agreement with the Directorate of Hydraulic Facilities (DAH).

Some are also deployed for the feasibility study of the future bridge or tunnel across the Strait of Gibraltar between Morocco and Spain. This network has enabled the recording of about 40 accelerograms following earthquakes of magnitude $\geq 4.0$. These recordings are currently being analyzed and processed to obtain response spectra and an attenuation law specific to seismic regions in Morocco.

Accelerometry of urban tissue - shakemaps: The second set of strong motion instruments is deployed mainly in the larger urban Centers. The objective of this second set is to provide estimated local intensity or acceleration maps in near real time. Stations are installed to help assess the shaking caused by a significant earthquake on different types of soils within urban centers. These local maps are intended for use by intervening authorities to help optimize and guide rescue and relief efforts and for a post-earthquake and recovery response. They are also used to provide timely information to decision-makers, the public, scientists and the private sector, as well as enabling simulations for preparatory exercises and disaster planning. These "shakemaps" (Wald et al., 2005) are to appear on the screens few minutes after the occurrence of a significant earthquake, at the command posts of risk management authorities and also on the INGM website. They are updated as new data become available.

The Shakemap warning system being put in place at the INGM is based on the following components: a fairly large seismic network covering the seismogenic sources, a network of accelerographs currently deployed in seven urban centers (Figure 7) and a system of analysis and processing as well as seismic databases. This will enable the production of shakemaps that are of great importance to seismic risk management authorities and mark a new and decisive phase in seismic information reporting in the country. Thus, for any earthquake of magnitude $M \geq 4.0$, this system is to produce maps describing the distribution of estimated seismic intensities in different localities around the epicentral zone of the earthquake.

So far, 50 accelerographs equipped with network-connection boards have been acquired, 18 of which have been installed in the cities of Al Hoceima, Nador, Fès, Tangier and Tétouan, while a minimum of 6 instruments will soon 
Abdelouahad Birouk et al.

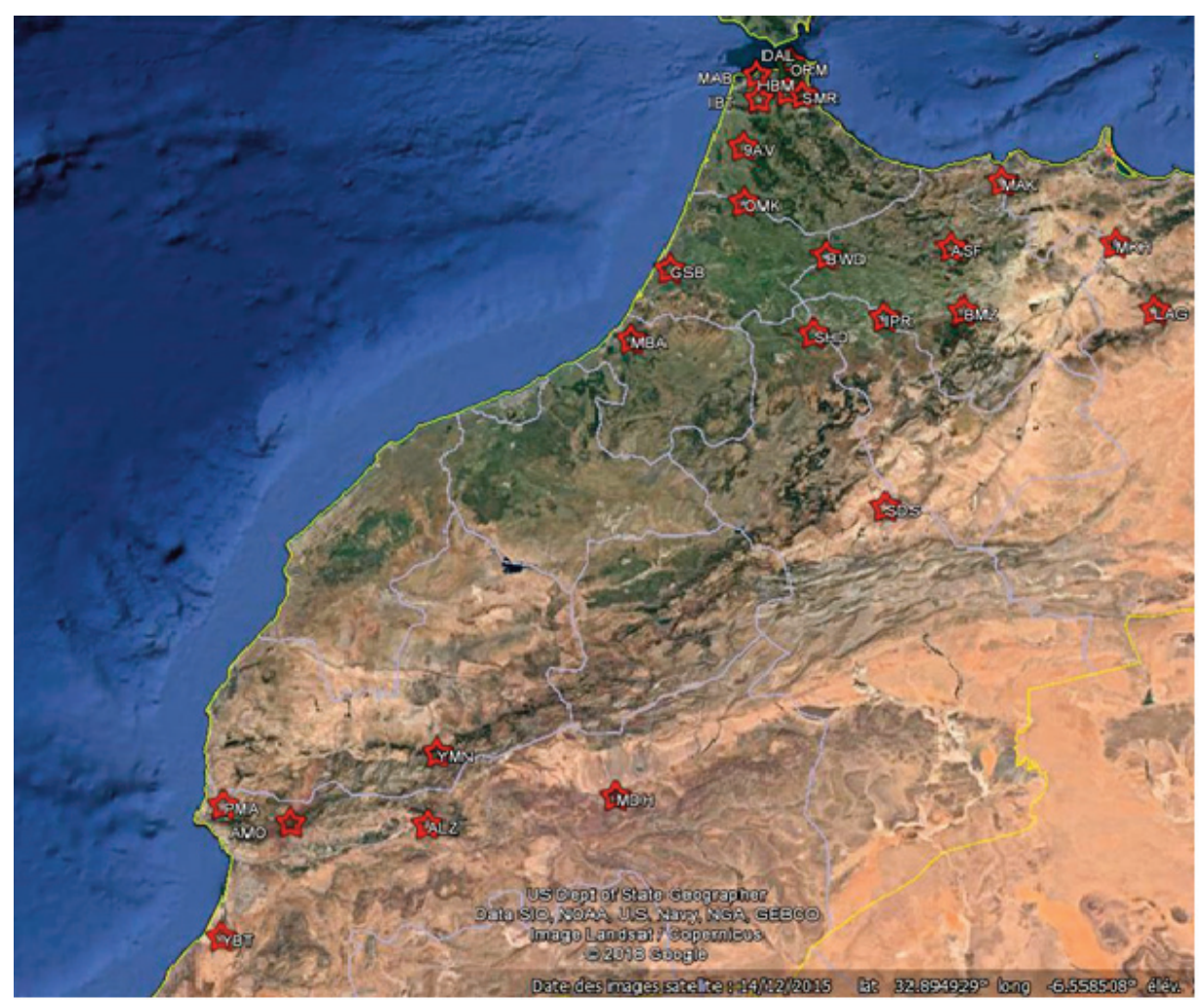

Figure 6. Strong-motion stations (red stars) used for large-infrastructures monitoring in the northern provinces of Morocco (projected on a Google Earth image).

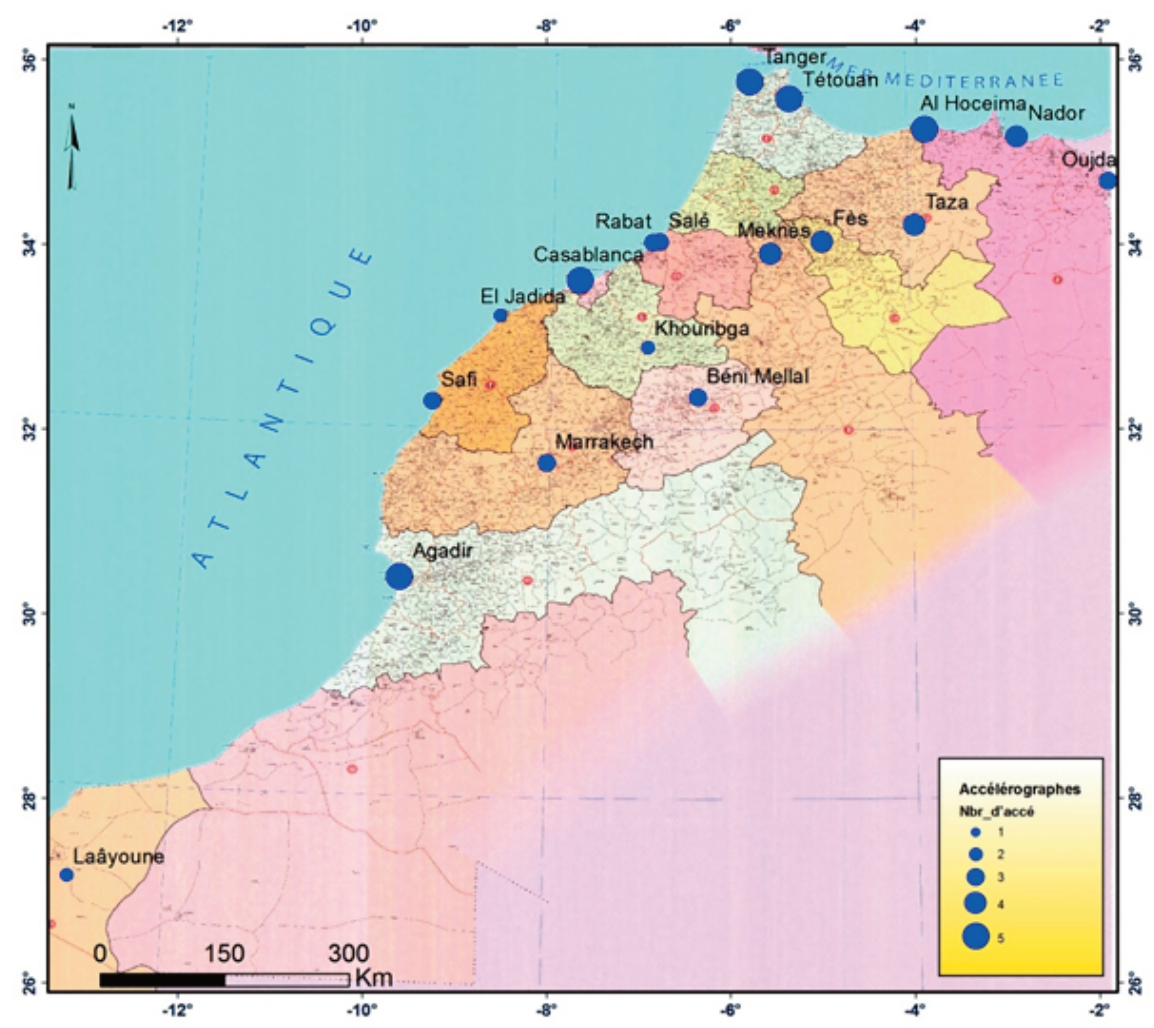

Figure 7. Network of urban strong motion instruments being deployed in the main cities of the country. The diameter of the circles is proportional to the number of accelerographs to install per city. 


\section{Monitoring earthquakes and Tsunami in Morocco}

be deployed in the city of Agadir and the remainder will be installed shortly thereafter. Theses accelerographs will be connected to the Antelope system via internet, for data acquisition and shakemap automatic calculations in near-real time.

The produced shakemaps (e.g. Figure 8) are based on the hypocentral parameters automatically determined by the central recording system, and using either actual accelerometric recordings obtained in zones equipped with accelerographs or soil motion prediction equations in zones where there are no accelerographs [e.g. Akkar \& Bommer 2010]. When available, Vs30 velocities are used to take into account site amplifications, otherwise site conditions are assessed using the Wald and Allen (2007) method which helps deriving maps of seismic site conditions using topographic slope as a proxy.

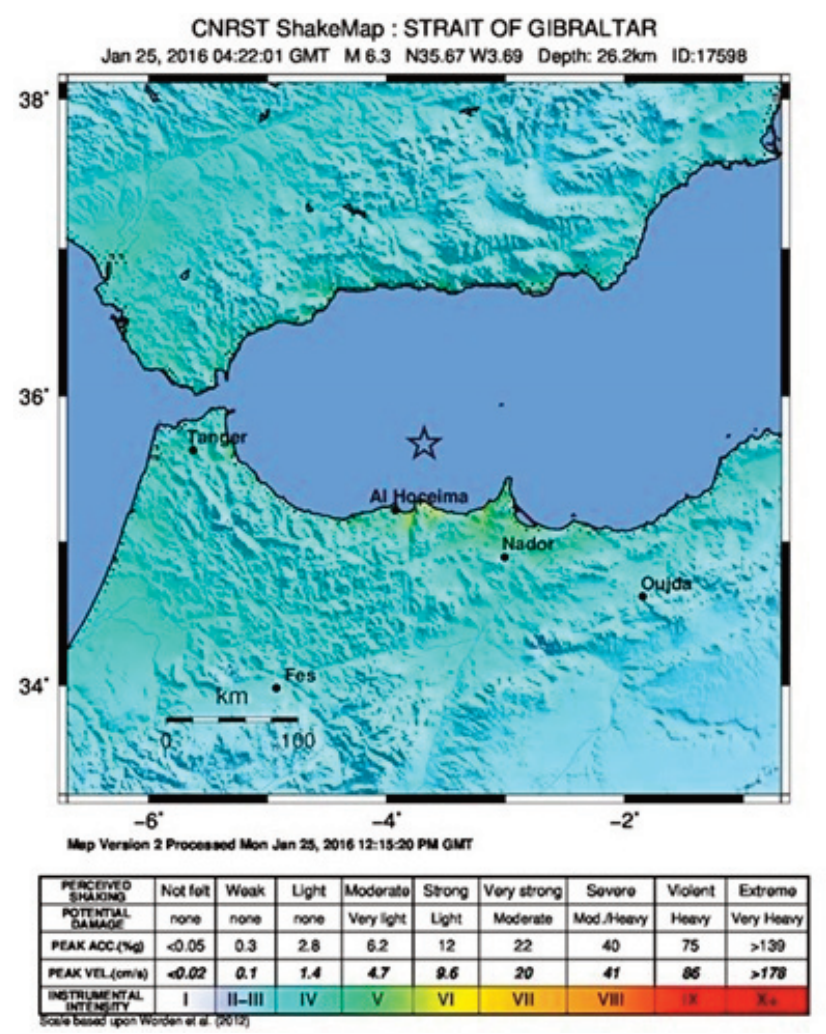

Figure 8. Example of a Shakemap of instrumental intensities calculated for the January 25, 2016 earthquake of magnitude 6.3 that occurred offshore the Al Hoceima region (North of Morocco). After completion of the deployment of the projected urban accelerometers, much more detailed (finer scale) maps should be produced.

\subsection{Tide-Gauges Network}

For the sake of sea level monitoring, the INGM is deploying a new network of tide-gauges, which combined with the real-time seismic network and an already installed tsunami analysis system, will help in providing early warning against tsunami. There are currently two functional tide gauges deployed at the Casablanca and Saidia harbors with a third planned for the port of Agadir. It is worth mentioning that in Saidia, two tide gauges were installed side by side, one of which was donated and co-installed by the Joint Research Centre (JRC-EC) in the framework of a project of the European Community [Annunziato et al., 2016]. By the end of 2019, this network is expected to reach seven real-time telemetered digital tide gauges (Figure 9). 


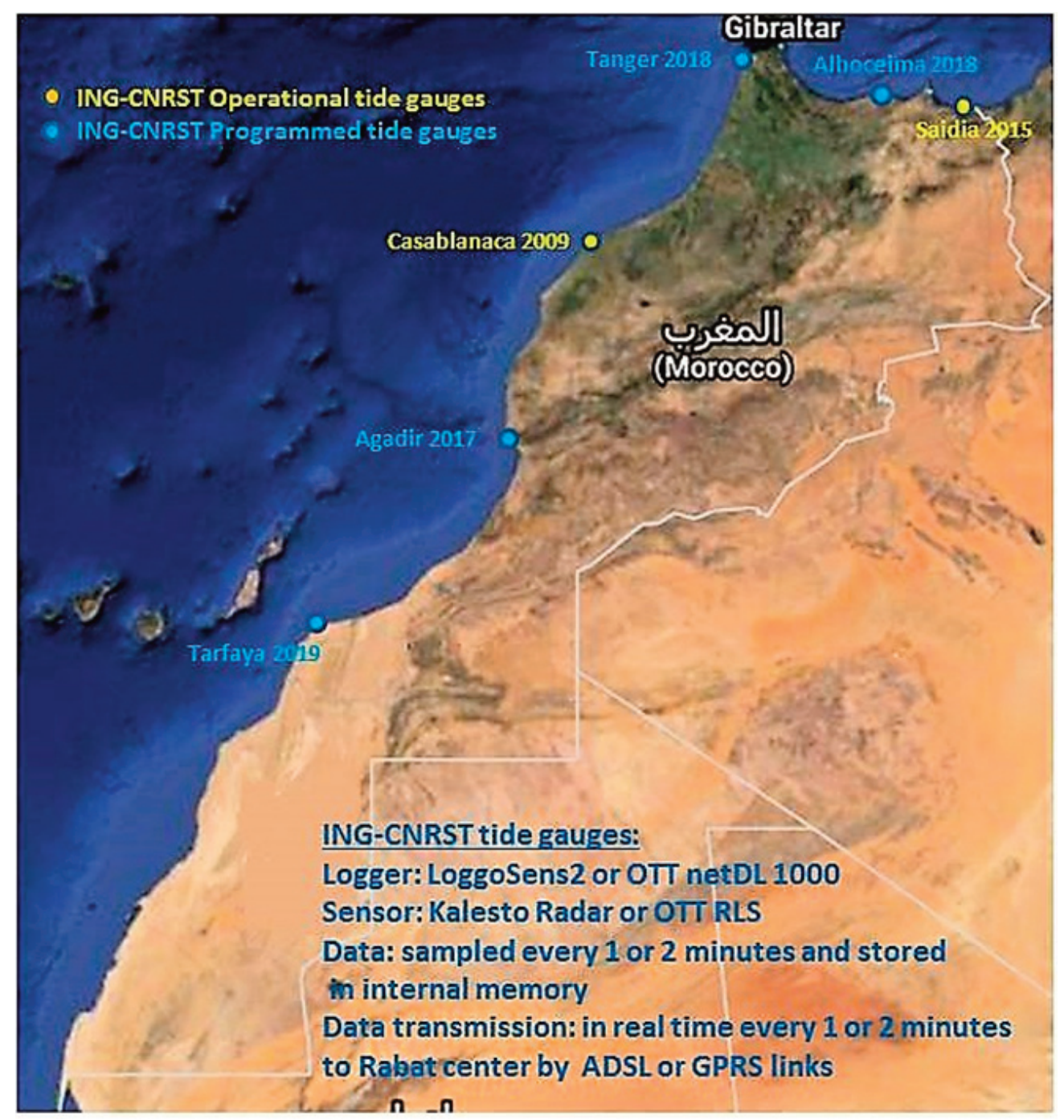

Figure 9. Network of tide-gauges for sea-level monitoring, operational gauges -Casablanca and Saidia are the yellow circles, the others (light blue circles) are planned for installation in the upcoming 2 years.

\section{Operations}

\subsection{Seismic surveillance and Monitoring within the National Territory}

Since 1993, the Government of Morocco has commissioned the National Institute of Geophysics (INGM) with the mission of the seismic surveillance of the Morocco territory. For this purpose and thanks to its real-time telemetered seismic networks, the INGM has set up a $24 / 7$ surveillance to help monitor the seismicity of the national territory and to give seismic communications in case of a significant earthquake.

The INGM also carries out an awareness mission on seismic risk to the population. It initiates schoolchildren, high school and university students to safety measures recommended for people in case of a major earthquake, trusting that these students will then relay the acquired information to their families. The seismic data collected by the National seismic network also feeds databases which are used in scientific studies that contribute to the effort of prevention and mitigation of seismic risk at the national level.

Since its installation and the beginning of its operation in 2012 and so far, the new network has helped send out more than 200 seismic warning messages to authorities in charge of seismic risk and has helped to record and locate thousands of earthquakes in Morocco and its in neighboring regions, not to mention non-located events, quarry blasts and recorded teleseismic events that can be used for research purposes. 
The seismic surveillance was established by order of the Prime Minister in 1993 and is ensured by about twenty scientists and technicians who take turns to ensure a $24 \mathrm{~h} / 7$ presence. Two technicians (a principal and an assistant) are present continuously at the INGM premises and take turns during working and non-working hours following a rotation scheme. Scientists, meanwhile, are present during working hours and remain on call during non-working hours so that they can be called upon to regain urgently the Institute in case of an earthquake.

The Central recording unit enables rapid data processing by automatically detecting and analyzing seismic phases and by associating events. Once an event is confirmed, its hypocentral location and magnitude are calculated and it is then declared in real-time as a seismic event. A first notification is communicated to INGM managers by email and SMS phone messages. The technicians and the scientist on duty then perform a manual check that takes about 15 to 30 minutes. A warning message is then sent by fax to all potential users. This hypocentral determination is also posted on the INGM website (http://cnrst.ma/index.php/fr/unites-et-services/mutualisation-et-services/ing; which is currently under reconstruction and which will most certainly contain the same function). Since 2007, agreements have been passed with partner seismological centers in Portugal and Spain for two-way exchanges of real-time seismic data.

\subsection{Tsunami warning: tide gauges and Tsunami Analysis System}

Morocco's coasts are exposed to tsunami risk both from the Atlantic Ocean and the Mediterranean side [Kaabouben et al., 2009]. This risk is clearly highlighted and demonstrated both by historical data [e.g. El Mrabet, 2005] and by numerical modeling studies [e.g. Benchekroun et al., 2013]. The high level of exposure and vulnerability along the coastline can unfortunately result in a devastating tsunami impact. Since 2006, the INGM as an institution in charge of the seismic monitoring and warning has begun actions for the assessment of tsunami risk (hazard and vulnerability) on the Moroccan coasts and has undertaken efforts to put in place an early warning system for tsunamis. Thus, the current tide gauges network is used to measure in real time the sea level along the coast in order to help confirm or refute the occurrence of a tsunami.

A third component of a Tsunami Early Warning System is the Automatic Tsunami Analysis Subsystem; a software that processes seismic and tide gauge data (tide and wave filtering) in real time and helps confirm or deny the occurrence of a tsunami. Once a tsunami alert is validated by the operator, the system allows sending alert messages to a number of recipients, specifying the arrival time of tsunami waves and their heights at certain points on the coast. These types of analysis systems are complex and designed for regions of the world where tsunamigenic sources are close to the coast leaving only a short time for warning. This is why in case of a significant marine earthquake and before sending the alert, these systems rather than calculating in real time the tsunami wave arrival time and their heights, use pre-calculated scenarios on 3-dimensional grids for all areas to evaluate (starting from the parameters of the earthquake), the possibility of the generation of a tsunami.

Thus, once the seismic network detects an earthquake (coordinates, magnitude and time of origin) the analysis system searches the database for scenarios that can represent it properly. The system sends out alert messages based on the selected scenarios but remains tuned in to real time tide gauge measurements to cancel or confirm the alert, with a possibility to correct the digital model (introduction of correction factors on the arrival time and the height of the waves).

Thus, the analysis system called Tsunami Analysis Tool (TAT) (http://webcritech.jrc.ec.europa.eu/TATNew_web/) developed by the Joint Research Center (JRC) of the European Commission is already installed at the INGM data center and is partially operational. The TAT is a tool for analyzing and assisting with the real-time assessment of tsunami hazard due to sources in the North Atlantic and the Mediterranean and helps in deciding whether to send tsunami alerts [Matias et al., 2013].

Throughout these efforts, the aim is to equip the INGM with the necessary tools so that it will start acting in a near future as a tsunami early warning center for the country. The TAT was tested in 2015-2016 when INGM scientists participated to the European Commission's GTIMS-2 project in which they exercised on the task of preparing rapid reports on large earthquakes that occurred around the Globe and that could possibly generate tsunamis (https://drmkc.jrc.ec.europa.eu/partnership/Scientific-Partnerships). 


\section{Abdelouahad Birouk et al.}

\section{Conclusions and future developments}

The new networks installed in Morocco have made it possible to monitor the seismic activity at the national level 24 hours a day, to systematically send warning messages to authorities in the shortest possible time in the advent of an earthquake with a magnitude greater than or equal to 3.5 or less than this threshold, if it is felt by the population. The INGM has thus, been instrumental in contributing to the reduction of seismic risk especially during the 2016 seismic crisis of $\mathrm{Al}$ Hoceima.

The seismic networks have also allowed to improve our knowledge about seismic activity in Morocco through the recording and location of several thousand earthquakes in Morocco and its neighboring regions, thus considerably extending the seismic instrumental database available, which is very beneficial to hazard, to seismic zoning and to various seismological studies in Morocco.

The new network, currently installed, includes in a first phase, 48 seismic stations of which 2/3 are broadband, in addition to two international broadband observatories and a seismic array comprising 10 stations spread over two concentric circles. This network uses new technologies and has made significant improvements in the quality of the recorded seismic signals, detections and locations as well as in improving seismic communication times.

It is planned in a next phase to add about forty additional real-time telemetered seismic stations to densify the network in regions with high seismicity, which will allow reducing the threshold of detectability, reducing the number of non-located events and improving the accuracy on the location of earthquakes. This is very important for the seismic warning system, especially for monitoring seismic crises and for communicating shakemaps to the concerned authorities. This is also important for the short-term recording of microseismicity in seismic risk zones, allowing to better characterize the seismogenic zones and beyond the assessment of the seismic hazard and zoning in the national territory.

Two components of the currently installed tsunami warning system are satisfactory, namely: 1- the real-time seismic telemetry network part, to the extent that the latter will eventually be completed soon and thanks to realtime seismic data exchanges with neighboring countries, 2- also the tsunami analysis system (TAT). However, the tide-gauges network remains quite small. The installation of at least another five more digital tide-gauges along the Atlantic and Mediterranean coasts is definitely required. This would help allow sufficient tsunami warning time to alert the population in time and allow them to evacuate to safer areas.

Continuing to develop real-time exchanges of seismic and tide-gauges data with neighboring countries is essential. Also access to other tide gauges data of the region thanks to the TAT tool of the JRC center currently available at the INGM, must continue through scientific and technical cooperation. It will also be necessary to maintain and further develop cooperation with the IOC-UNESCO in charge of the establishment of Tsunami regional early warning centers around the world.

Finally, the INGM acquired a first set of 14 GPS instruments that it intends to deploy for the setting up of a full new network of about 50 permanent GPS stations in Morocco in the near-future.

Acknowledgements. The authors thank all INGM scientists, technicians, analysts, and the directors and staff of the CNRST administration who have contributed to the conception, design and deployment of the seismic and tide-gauges networks described in this paper, and those who analyzed data and worked on developing the Morocco monitoring and surveillance system. We also thank two anonymous reviewers and Lucia Margheriti who as a reviewer, provided constructive comments that helped improve this manuscript.

\section{References}

Akkar, S. and J. J. Bommer (2010). Empirical equations for the prediction of PGA, PGV and spectral accelerations in Europe, the Mediterranean region and the Middle East, Seism. Res. Let., 81 (2), 195-206.

Annunziato A., Galliano D., Bonaita M. (2016), Report on the deployment and first year of work of the IDSLs in the Mediterranean area, JRC Technical report, the European Commission's science and knowledge service, pp. 56; doi:10.2788/470647

Benchekroun S., R.Omira, M. A. Baptista, A. El Mouraouah, A. Iben Brahim and E. A. Toto (2013). Geomatics, Natural 
Hazards and Risk: Tsunami impact and vulnerability in the harbour area of Tangier, Morocco, Geomatics, Natural Hazards and Risk, 1-23, doi: 10.1080/19475705.2013.858373.

Bensaid, I., T.E. Cherkaoui, F. Medina, B. Caldeira, E. Buforn, A. Emran and Y. Hahou (2012). The 1992 Tafilalt seismic crisis (Anti-Atlas, Morocco), J. Seismol, 16, 35-53 doi:I10.1007/s10950-011-9248-5.

El Mouraouah, A., A. Iben brahim, M. Kasmi, A. Birouk, T. El M’rabet, E.M. Zouine, R. El Mouraouah, E.A. Toto, M. Benammi, M. Hafid, S. Haida, L. Dasser, A. Talhaoui, Y. Cheddadi and N. Hlali (2004). Le séisme d'Al Hoceima du 24 Février 2004 : Surveillance sismique et analyse préliminaire : situation au 31 mai 2004 : Report Ed. by CNRST-CEPRIS, 162.

El Mrabet, T. A. (2005). The Great earthquakes in the Maghreb region and their consequences on man and environment (in Arabic), T. A. El Mrabet (Editor), 478.

Iben brahim, A., B. Tadili, M. Kasmi, M. Ramdani, N. Jabour, A. Birouk, M. El Idrissi Dafali, A. El Mouraouah, T. El Mrabet and L. Ait Brahim, (1994). Case study: The Al Hoceima earthquake crisis of May-June 1994, European Seismological Commission, XXIV General Assembly, Athens, September 19-24, 119.

Iben brahim, A., A. El Mouraouah, A. Birouk, and M. Kasmi (2004). seismic map of Morocco, 1900-2001, Ed. by the Centre Euroméditerranéen de Prévention du Risque Sismique (CEPRIS) \& l'Agence Nationale de la Conservation Foncière, du Cadastre et de la Cartographie, Morocco, scale 1.500.000.

Iben brahim, A., A. El Mouraouah, A. Birouk and M. Kasmi (2009). Towards the Establishment of a National Tsunami Warning Center in Morocco, EMSC-Newsletter, $\mathrm{N}^{\circ} 23 /$ April 2009, 17-19.

Kaabouben, F., M. A. Baptista, A. Iben brahim, A. El Mouraouah and E. A. Toto (2009). On the Morocco tsunami catalogue, Nat. Hazards Earth Syst. Sci., 9, 1227-1236. www.nat-hazards-earth-syst-sci.net/9/1227/2009/

Kariche, J., M. Meghraoui, Y. Timoulali, E. Cetin and R. Toussaint (2018). The Al Hoceima earthquake sequence of 1994, 2004 and 2016: Stress transfer and poroelasticity in the Rif and Alboran Sea region, Geophys. J. Int., $212,42-53$.

Matias, L. M., T. Cunha, A. Annunziato, M. A. Baptista, and F. Carrilho (2013). Tsunamigenic earthquakes in the Gulf of Cadiz: fault model and recurrence, Nat. Hazards Earth Syst. Sci., 13, 1-13, https://doi.org/10.5194/nhess-131-2013

Michelini, A., L. Margheriti, M. Cattaneo, G. Cecere, G. D’Anna, A. Delladio, M. Moretti, S. Pintore, A. Amato, A. Basili, A. Bono, P. Casale, P. Danecek, M. Demartin, L. Faenza, V. Lauciani, A. G. Mandiello, A. Marchetti, C. Marcocci, S. Mazza, F. M. Mele, A. Nardi, C. Nostro, M. Pignone, M. Quintiliani, S. Rao, L. Scognamiglio, G. and Selvaggi, (2016). The Italian National Seismic Network and the earthquake and tsunami monitoring and surveillance systems, Adv. Geosci., 43, 31-38, https://doi.org/10.5194/adgeo-43-31-2016.

Pelaez, J. A. M. Chourak, B. A. Tadili, L. Ait Brahim, M. Hamdache, C. Lopez Casado, and J. M. Martinez Solares (2007), Seismo. Res.Lett., 78, N. 6, 614-621.

Peterson, J. (1993), Observations and modeling of seismic background noise, U.S. Geol. Surv. Open-File Rept. 93322.

Wald, D.J., C.B. Worden, K.W. Lin, and K. Pankow (2005), ShakeMap manual: technical manual, user's guide, and software guide, U. S. Geological Survey, Techniques and Methods 12-A1, 132, http://pubs.usgs.gov/tm/2005/12A01/.

Wald, D. J., and T. I. Allen (2007), Topographic slope as a proxy for seismic site conditions and amplification, Bull. Seismol. Soc. Am. 97, 1379-1395. 